\title{
Long-run Social and Economic Responses of Fertility in the United States
}

\author{
YIANNIS P. VENIERIS and DOUGLAS B. STEWART*
}

\begin{abstract}
Based on the results of an econometric analysis, the paper looks into the dynamic response of fertility behaviour in the United States, to changes in some of its determinants. Specifically, the effect of current and past marriage rates on fertility has been studied. In doing so, the role of permanent income and the divorce rate on the marriage rate, and through it, on fertility, has also been examined.
\end{abstract}

The purpose of this paper is to present the results of an econometric study in the long-run behaviour of fertility of the United States. In the past twenty-five years interest in the field of economic demography has greatly intensified. This is due, at least in part, to the exciting dialogue among several investigators of whom Becker and Easterlin hold prominent positions. Their efforts have culminated in the proposal of two different constructs: that is, the "Chicago-NBER" [Becker (1960); Becker and Lewis (1976), Gregory et al. (1972); Butz and Ward (1977), and Ward and Butz (1980)] and the "Relative Income" [Easterlin (1968, 1969, 1972, 1973); Lee (1974); Watcher (1975); and O'Connell (1977)] . Although these studies are useful in that they focus on the endogenous character of fertility, either in the context of partial or general equilibrium, it appears that with a few exceptions [Becker (1960); Easterlin (1969); Schultz (1971); Venieris et al. (1973) and Ward and Butz (1980)] they have not addressed adequately, at least empirically, the dynamic aspects of the problem. Moreover, the decisions in relation to both completed family size as well as timing of births are viewed as falling exclusively in the domain of economics and are usually assumed to depend on expectations as to how a number of economic variables (notably various forms of aggregate or disaggregate family income) evolve

* The authors are respectively, Professor and Associate Professor of Economics at San Diego State University. A longer version of this paper was read in the invited annual session of the International Econometric Society. We wish to acknowledge our two unknown referees for helpful comments and suggestions. The remaining errors reflect only our shortcomings. 
over time. This approach, however, ignores the social environment of the economic actors and how this environment affects their decisions in regard to fertility, thereby resulting in a misspecified model due to missing variables. Under these circumstances, even if one subscribes to scientific positivism, it can be argued that the recognition and introduction of variables that reflect social considerations into the model that purports to explain the behaviour of fertility will enhance its predictive power by avoiding this unfortunate problem of misspecification. Our purpose, albeit modest, is to introduce in the fertility model some variables which may decrease the misspecification bias in question.

In what follows, Section II discusses the model we shall use and its rationale. Section III presents and discusses the estimates and Section IV draws the conclusions.

The simplest scheme that can be used empirically and defended theoretically (Lee 1977) in relation to fertility is the stock adjustment model. Accordingly, we assume that the change in fertility at any time $t$, is proportional to the difference between its currently desired $\left(F_{t}^{*}\right)$ and the actual rate experienced during last period $\left(F_{t-1}\right)^{1}$, that is,

$$
\Delta F_{t}=\lambda\left[F_{t}^{*}-F_{t-1}\right], 0<\lambda<1
$$

which may also be written as

$$
F_{t}=\lambda F_{t}^{*+}(1-\lambda) F_{t-1}
$$$$
\cdots
$$

At the micro level, the problem of determining the desirable level of fertility, at any time $t$, is assumed to entail a decision about the completed family size and another about the distribution of the implied number of births over time. A recently proposed solution (Ward and Butz 1980) is based on a constrained maximization of an intertemporal objective function which yields a sequential decision rule that involves a number of forward-looking operators. The implicit assumption used is that the utility functions of the various economic actors are independent of each other.

Although this approach may facilitate, a priori, the process of aggregation, nevertheless, it ignores how social roles, reciprocal obligations and mutual expectations affect the behaviour patterns of the economic actors during the exercise of their choice (Hayakawa and Venieris 1977). On the other hand, the recognition of interdependence of preference relations raises a number of prohibitive problems of aggregation whose solution entails various degrees of arbitrariness and/or ad hoc theorizing. In this spirit, we shall assume away any aggregation problems. Moreover, we shall also assume that the desired rate of fertility $\left(F^{*}\right)$ is a function of the marriage rate $(M R)$, the level of income $(Y)$, the female unemployment rate $(F u \eta)$, the ratio of urban to rural population (Urb/Rur), the divorce rate $(D R)$, the level of oral contraception sales $(O C)$ and some other variables which reflect changes in the compositional characteristics of the population $(P C)$; that is,

$$
F_{t}^{*}=F(M R, Y, F u \eta, U r b / R u r, D R, O C, P C) \quad \ldots \quad \ldots
$$

In particular, given our present institutions and the biological fecundity of women, the desired fertility rate may be expressed, as a first approximation, as a function of the stream of marriage rates which, at time $t$, includes all married women who are capable of bearing children; ${ }^{2}$ that is,

$$
\begin{array}{ll}
F_{t}^{*}=b+\sum_{j} a_{j} M R_{t-j}, & a_{j}>0 \text { for } j<\eta \\
& a_{j}=0 \text { for } j \geqslant \eta
\end{array}
$$

The coefficients $a_{j}\left(=\frac{\partial F_{t}^{*}}{\partial M R_{t-j}}\right)$ show the temporal contribution of marriage rates to today's level of fertility. In a sense, they capture the distribution of conceptions and births over time that will result in the desired completed family size. The restrictions placed on these coefficients are dictated by the biological fecundity of women. Clearly, the assumed polynomial in time $a_{j}\left(a_{j} ; j=0,1, \ldots, \eta\right)$ is not monotonic. This precludes the case of a hyperbolic behaviour. Although we can safely assume the polynomial is positive for any value of $j$ which is less than $\eta$, we cannot advance any a priori hypothesis as to the number of its local maxima or, what is

${ }^{2}$ The average age of women entering marriage for the first time has been for more than the last half century between twenty and twenty-one. Moreover, since the average age of women experiencing menopause is in the neighbourhood of 45-49 years of age, it follows that a reasonable estimate for $n$ can be found in the interval $[24, \ldots, 27]$. This specification requires also that $a_{n}=0$. In relation to the behaviour of $a_{j}$ 's, since total fertility is defined to include not only the first but also all subsequent births, an argument can be made that the $a_{j}$ 's follow a pattern generated by a higher than second degree polynomial in time. Early experimentation with third and fourth degree polynomials did not yield reliable results. Finally, it could be argued that since marriage rates depend on income, it would be preferable to express $F_{t}$ as a function of the latter variable. Such a specification, however, would not allow to estimate separately the effects of income on fertility from the effects of income on marriages.

${ }^{1}$ Although there might be some controversy as to the choice of the appropriate variable to be explained, Easterlin's arguments (1972) in favour of total fertility seem to be compelling. 
the same, as to how often the sign of its derivatives with respect to time changes. This issue has to be resolved empirically (see footnote 2 ).

The rest of this section will be devoted to discussing the hypotheses and their rationale in regard to the variables that appear in Equation (2) and also how Equation (3) has to be augmented to reflect these hypotheses.

One of the most controversial explanatory variables in the equation of fertility is the variable income. This controversy is associated first, with the qualitative effect of this variable on fertility, second, with the definition of income to be used in the fertility equation and third, with the functional specification of the relationship between these two variables.

With regard to the qualitative impact of income upon fertility, it has been argued that children can be treated as a class of durables and consequently, traditional demand analysis can be applied to the behaviour of births. According to this view, assuming that babies are "normal' goods, the theoretical expectations should be that the income elasticity of fertility is positive (Becker 1960). It has also been suggested however, that the quality elasticity may be so high, over the relevant range of income, that the income elasticity of the quantity of children may turn negative (Okun 1960). A third view (Venieris et al. 1973) has also argued in favour of the negative income elasticity.

This difference in opinion, however, can be reconciled if one considers the opposing views in an historical context. Indeed, the characterization of a good by a positive or a negative income elasticity depends on the level of income in the neighbourhood of which the elasticity is estimated. Should one consider levels of income that differ substantially from each other, the likelihood is that the demand for the good in question would be characterized by income elasticities of different signs.

In the case of our study, the sample spans a period of eighty years. During this period changes in technology and large increases in income have resulted in a considerable increase in the range of goods and services over which the consumers can exercise their choice. The outcome of such a broadening of the consumers' choice set is also the increase in the number of goods which can be considered as substitutes to each other and this, in turn, makes it possible that the demand for a number of these goods will decline. Furthermore, with very few exceptions, any good may be found to be inferior at some level of income. These arguments suggest that a change in the sign of the income elasticity of fertility is possible. Moreover, they shed light on the specification of the relationship between fertility and income. In particular, they imply that the Engel's curve may be specified as a parabolic relation to accommodate a change in the sign of the income elasticity of fertility.

From an empirical point of view these thoughts are corroborated also by our sample. For instance, it has been estimated that during the period prior to 1958 , the income elasticity of fertility was positive and it turned negative for the period after that year. In fact Chow tests have not supported the null hypothesis even for the period 1955-1967 when the sample consists of monthly observations.

Easterlin and his associates, have attempted to explain the decrease in fertility rates during the Sixties in terms of a decline in the relative income of young couples who contemplate becoming parents. This raises two distinct issues. First, what definition of income should be used in the fertility equation and second, the appropriate specification of the relative income. In relation to the latter issue, it is reasonable to ask against whose absolute income one should define the relative concept. Easterlin's argument favours the income of the parents and on the basis of this comparison he finds that the relative income of the young couples has been declining. However, the appropriateness of this comparison may be questioned. Because first, to assess if and to what extent there is any difference in the behaviour of fertility one should compare the income of the new households with that of the old ones when the members of the latter were of the same age and, more significantly, second, the relative income should be defined neither in terms of the recent history nor in terms of the past one of the parent's income. Instead, it should be defined in terms of the income of the "significant others". as sociologists as well as economic theory and empirical evidence have established, [Miller (1963); Kelly (1968); Newcomb (1968); Festinger (1968) and Hayakawa and Venieris (1977)] . Indeed, it is neither reasonable to assume that the peer group of the prospective young parents includes their own parents nor is it clear that the phenomenon of spatial mobility or the comparatively short memory of the prospective parents allow the type of comparisons advocated by Easterlin.

In regard to the definition of income to be used, since children may be considered as a class of "durables", given the appropriate literature (e.g. Friedman 1957), an argument can be made in favour of the use of permanent income $\left(Y_{p}\right)$. In this relation, the ideal measure would be the permanent income of the household disaggregated into that of husband and wife. Unfortunately, this measure is not available for the time span of our study. Instead, we have used, as a surrogate, the per capita version of permanent income.

Given our previous remarks, the relationship between the desired level of fertility and permanent income will be specified as parabolic. For the sake of comparison, however, we shall also present some estimates which correspond to a linear specification of the relationship in question.

Our argument so far has focused upon the effects of income on the level of fertility or the number of children. It can be argued, however, that income affects also the timing of births (i.e. how births are distributed over the productive span of marriage). This means that income affects fertility not only directly but also indirectly through its influence on the contribution of the various marriage rates to the present level of fertility [i.e., through its effects on $\left.a_{j}\left(\frac{\partial F_{t}^{*}}{\partial M R_{t-j}}\right)\right]$. This latter effect 
can be captured through the parameterization of the coefficients $a_{j}$ (see Equation 3).

In econometric studies of fertility behaviour, sources of tastes and the effects of social institutions are generally ignored falling usually in the category of the given. This is so not for lack of appropriate theorizing but for lack of measurements over time of variables which express changes in the various social dispositions. This claim, however, cannot be used in general for although, to use an example, it appears that the society at large has changed its attitude toward individuals who have been divorced, unfortunately, the effect of the divorce rate on fertility has not, as yet, been adequately gauged. A divorce subjects both husband and wife to financial and emotional drain which is usually exacerbated by the presence of children. Given the new social perceptions about divorce and also the increase in their frequency and number, risk averse individuals will temper their demand for children. This is usually expressed either in terms of a decrease in the desired completed family size or in terms of a postponement of its completion or in terms of both. The former effects may be captured by introducing the divorce rate as an independent variable in the fertility equation. The latter may be captured by parameterizing once more the $a_{j}$ 's and make them also a function of divorce rates.

A similar argument can be made regarding the effects of contraception on fertility; that is, contraception may affect either the level of the desired completed family size or its distribution over time or both.

In cross-sectional studies, families are viewed as producing child services as well as other commodities by using the time of husband and wife along with other complementary inputs. This view, however, may reflect, to some extent, the recent advances we have all witnessed in the field of women's rights. Given, however, the time span of our study, we do not expect that the recently observed evolution in the relationship of spouses will affect the behaviour of fertility. Instead, we believe that within our sample period, with the exception of the last few years, the production of child services is primarily (if not exclusively) a wife's-time intensive good. On this basis, it can be argued that the opportunity cost of having a child declines (increases) as the female unemployment rate increases (decreases). A similar argument was also used by Mincer who cast it in terms of female participating rates. Mincer found that a decrease in female participation rates is associated with an acceleration in the family formation and completion (Mincer 1966). But changes in the female participation rate or, for that matter unemployment, may also be technically related only to changes in the timing of conceptions and births rather than to the long-run changes in the completed family size. This issue, therefore, can be decided only with reference to empirical evidence and not a priori. Availability of data allow us to experiment only with the variable female unemployment rates.

Equation (2) suggests also that the desired level of fertility is affected by the ratio of urban to rural population. The inclusion of this variable stems from the recognition that the historic immigration from rural to urban environments has contributed considerably to the long-run decline in fertility (e.g. Kuznets and Rubin 1954); (Thomas 1960).

Finally, Equation (2) includes a population compositional variable (PC) which although appears to affect fertility it has, nevertheless, been largely ignored by the literature. The influence of major wars and the attendant changes in the mix of military and non-military pepulation gets little attention - even frum (Easterlin 1973) who at one point focuses his analysis on the explanation of the post World War II baby boom. If the influence of the war years was fully reflected by other variables, there would be no need to consider the population - composition effect of the military. But this hardly seems to be the case. The uncertainty facing a military couple - especially during periods of armed conflict - is not fully compensated by the types of variables discussed so far. Nor is it the full weight of post-war unification of military couples reflected by other variables. To capture these effects we have used two separate variables: the first, reflects the relative importance of the military and is expressed in terms of armed forces abroad as a percent of population (Armfab) whereas the second, involves the use of a post war dummy (PWD).

The previous remarks in relation to the explanatory variables of Equation (2) are summarized in the following two expressions:

$$
\begin{gathered}
F_{t}^{*}=b+\sum_{j} a_{j} M R_{t-j}+C_{0} Y_{p t-1}+C_{1} Y_{p t-1}^{2}+C_{2}(\text { Urb/Rur })_{t-1}+ \\
C_{3} \text { Armfab }_{t-1}+C_{4} \text { PWD }_{t}
\end{gathered}
$$

and

$$
\frac{\partial F_{t}^{*}}{\partial M R_{t-j}}=a_{j}=a_{j}\left(Y_{p t-1}, D R_{t-1}, O C_{t-1}, F u \eta_{t-1}\right)
$$

Expanding Equation $3 b$ in Taylor series and retaining only the linear terms we obtain

$$
a_{j}=\alpha_{j}+Y_{p t-1} \beta_{j}+D R_{t-1} \gamma_{j}+F u \eta_{t-1} \delta_{j}+O C_{t-1} \epsilon_{j} \quad \ldots
$$

In Equation (4) the polynomial $a_{j}$ is decomposed into five different polynomials; that is, $\alpha_{j}, \beta_{j}, \gamma_{j}, \delta_{j}$ and $\epsilon_{j}$ which are weighted with the variables unity, $Y_{p t-1}$, $D R_{t-1}, F u \eta_{t-1}$ and $O C_{t-1}$ respectively. The degrees of all these polynomials in time cannot exceed the assumed degree of polynomial $a_{j}$.

Substituting now Equation (4) into Equation (3a) and the resulting equation for $F_{t}^{*}$ into Equation (1), we obtain the expression for the fertility rate to be estimated: 


$$
\begin{aligned}
& F_{t}=\lambda b+\lambda \sum_{j} \alpha_{j} M R_{t-j}+\lambda \sum_{j} \beta_{j} Y_{p t-1} M R_{t-j}+ \\
& \lambda \sum_{j} \gamma_{j} D R_{t-1} M R_{t-j}+\lambda \sum_{j} \delta_{j} F u \eta_{t-1} M R_{t-j}+ \\
& \lambda \sum_{j} \epsilon_{j} O C_{t-1} M R_{t-j}+\lambda C_{0} Y_{p t-1}+\lambda C_{1} Y_{p t-1}^{2}+ \\
& \lambda C_{2}(\text { Urb/Rur })_{t-1}+\lambda C_{3} A_{r r m f c b_{t-1}}+ \\
& \lambda C_{4} P W D_{t}+(1-\lambda) F_{t-1}+u_{t}
\end{aligned}
$$

Our preceding discussion has already set the stage for the $a$ priori expected signs of the various coefficients. Explicitly, we expect all $\alpha_{j}^{\prime}$ 's to be positive and all $\gamma_{j}$ 's and $e_{j}$ 's to be negative. In relation to $\beta_{j}$ 's we expect their sum to be positive but not each and every $\beta_{j}$. In particular, since the opportunity cost of having a baby expressed either in leisure time or pecuniary terms or both - is different depending on the age of marriage and the age of the participants, we do not expect that all marriages will react the same way to a given change in income even if the income of the various couples is the same at the time of the change in question. Specifically, it has been argued [Becker (1960); Venieris et al. (1973) that the opportunity cost of the new prospective parents - expressed primarily in terms of income - and also that of older couples - expressed primarily in terms of leisure - is very high. An increase, in their income, therefore, will most likely result in a decrease in fertility. This suggests that the polynomial $\beta_{j}$ will assume negative values at the beginning and the end of its stream and positive ones in the middle. Regarding the behaviour of $\delta_{j} \mathbf{s}$, the relevant literature does not provide us with any fast guide. We have argued that the effect of female unemployment is positive. This might, however, depend on the perceptions of the couple as to the time length of unemployment. This last effect, however, may also be captured by the level of expected future income. Therefore, it is difficult to assess a priori the sign of this variable. Finally, we expect that the polynomial $a_{j}$ (i.e. the weighted sum of the previously mentioned polynomials - see Equation (4)) will be positive for all $j$ s.

An alternative specification of the fertility rate equation would be to introduce the variables $D R, F u \eta$ and $O C$ directly into Equation (3a) and abandon Equation (4). Substitution of the augmented Equation (3a) into Equation (1) yields:

$$
\begin{aligned}
& F_{t}=\lambda b+\sum_{j} a_{j} M R_{t-j}+\lambda C_{0} Y_{p t-1}+\lambda C_{1} Y_{p t-1}^{2}+ \\
& \lambda C_{2}(\text { Urb/Rur })_{t-1}+\lambda C_{3} \cdot \text { Armfab }_{t-1}+ \\
& \lambda C_{4} P W D_{t}+\lambda C_{5} D R_{t-1}+\lambda C_{6} F u \eta_{t-1}+\lambda C_{7} O C_{t-1}+ \\
& (1-\lambda) F_{t-1}+u_{t}
\end{aligned}
$$

The non-interactive specification of Equation (6) assumes that the variables $Y_{p}$, $D R, O C$ and Fu $\eta$ affect only the level but not the timing of births. For the sake of comparison we shall present estimates of both hypotheses as depicted by Equations (5) and (6).

Our empirical work is based on 78 observations spanning the period 1900 1977. The data sources on fertility, mairiage rates, divorce rates, income, female unemployment, armed forces abroad and rural and urban population are: U.S. Department of Commerce, Bureau of Census, (Various Issues).Data on contraception were collected from the various issues of Inc magazine and represent annual sales of oral contraception pills covering approximately the last twenty years of the sample period. This variable $(O C)$, therefore, is used interactively - with a dummy which assumes the values of 0 or 1 depending on whether there is information about the sales of oral contraception pills or not.

As we mentioned earlier (see Footnote 2) we have assumed that the polynomial $a_{j}$ is of second degree; that is,

$$
\alpha_{j}=k_{0}+k_{1} j+k_{2} j^{2}, j=0,1,2, \ldots, 24-27
$$

This assumption predicates the degree of all other polynomials (see Equation 4) which cannot be higher than second degree. Earlier experimentation convinced us that they too follow a parabolic pattern.

In Equation (5) and (6) with the exception of $M R_{t}$ and $P W D_{t}$ all other variables are predetermined. Moreover, $\mathrm{PWD}_{t}$ is exogenous. There might be, however, a question in relation to the variable $M R_{t}$. Given the restriction imposed by Equation (7), it is doubtful whether $M R_{t}$ will bias the estimates. At any rate, we have attempted to remove the potential source of bias by using an instrumental estimation procedure according to which $M R_{t}$ is substituted by its estimate $\hat{M} R_{t}$. The instruments used to estimate $\hat{M} R_{t}$ are $D R_{t-1}$, the level of income lagged one period, (total income - not permanent and not per capita), and the ratio of the percent of urban to total population lagged one period. The set of predetermined variables was selected by using Theil's criterion (Theil 1966).

In our effort to test whether the variable income should enter Equations (5) and (6) linearly or not, we have estimated Equation 6 without the term $Y_{p t-1}^{2}$. In doing so, the variables per capita income and divorce rate are introduced in their "permanent" version. ${ }^{3}$ Table 1 provides a summary of the various hypotheses tested

${ }^{3}$ The permanent form of these variables is derived as:

$$
Y_{p t}=\sum_{j=0}^{m} \mu(1-\mu)^{j} Y_{t-j} \text { and } D R_{t-j}=\sum_{j=0}^{m} \nu(1-\nu)^{j} D R_{t-j}
$$

The noise of these two variables appears to be fairly small. The $\bar{R}^{2}$ was maximized for $\mu=\nu=9$ and $m=3$. These estimates are maximum likelihood estimates. 
Table 1

Summary of Various Hypotheses Tested in the Context of Equation (6)

\begin{tabular}{|c|c|c|c|c|c|c|c|}
\hline \multirow{2}{*}{ Variables } & \multicolumn{7}{|c|}{ Equations } \\
\hline & (1) & (2) & (3) & (4) & (5) & (6) & $\left(7^{*}\right)$ \\
\hline Constant & $\begin{array}{r}-167.64 \\
(3.32)\end{array}$ & $\begin{array}{r}-168.34 \\
(3.45)\end{array}$ & $\begin{array}{r}-170.72 \\
(3.78)\end{array}$ & $\begin{array}{r}-164.59 \\
(3.21)\end{array}$ & $\begin{array}{r}-130.37 \\
(2.48)\end{array}$ & $\begin{array}{r}-119.86 \\
(2.28)\end{array}$ & $\begin{array}{r}-77.201 \\
(2.43)\end{array}$ \\
\hline$\sum_{j} M R_{t-j}$ & $\begin{array}{r}.488 \\
(3.43)\end{array}$ & $\begin{array}{l}.4538 \\
(3.26)\end{array}$ & $\begin{array}{r}.772 \\
(3.92)\end{array}$ & $\begin{array}{l}.6982 \\
(3.53)\end{array}$ & $\begin{array}{r}.574 \\
(2.99)\end{array}$ & $\begin{array}{r}.544 \\
(2.83)\end{array}$ & $\begin{array}{r}.432 \\
(2.75)\end{array}$ \\
\hline$\sum_{j}^{\sum j M R_{t-j}}$ & $\begin{array}{l}.0513 \\
(3.10)\end{array}$ & $\begin{array}{l}.07663 \\
(3.67)\end{array}$ & $\begin{array}{c}.0151 \\
(1.42)\end{array}$ & $\begin{array}{l}.0217 \\
(1.56)\end{array}$ & $\begin{array}{l}.0140 \\
(1.35)\end{array}$ & $\begin{array}{l}.00894 \\
(1.22)\end{array}$ & $\begin{array}{l}.00549 \\
(1.14)\end{array}$ \\
\hline$\sum_{j}^{2{ }^{2} M R_{t-j}}$ & $\begin{array}{l}-.00195 \\
(3.55)\end{array}$ & $\begin{array}{l}-.00310 \\
(3.83)\end{array}$ & $\begin{array}{l}-.00074 \\
(1.60)\end{array}$ & $\begin{array}{l}-.0011 \\
(1.83)\end{array}$ & $\begin{array}{l}-.0009 \\
(1.66)\end{array}$ & $\begin{array}{l}-.000734 \\
(1.63)\end{array}$ & $\begin{array}{l}-.000796 \\
(1.58)\end{array}$ \\
\hline$Y_{P, t-1}$ & & $\begin{array}{r}2.343 \\
(1.89)\end{array}$ & $\begin{array}{r}9.274 \\
(1.82)\end{array}$ & $\begin{array}{l}12.343 \\
(1.54)\end{array}$ & $\begin{array}{l}14.683 \\
(3.03)\end{array}$ & $\begin{array}{c}14.594 \\
(2.88)\end{array}$ & $\begin{array}{l}16.731 \\
(3.62)\end{array}$ \\
\hline$D R_{P, t-1}$ & & & $\begin{array}{c}-3.946 \\
(1.46)\end{array}$ & $\begin{array}{c}-4.776 \\
(1.74)\end{array}$ & $\begin{array}{r}-5.600 \\
(1.99)\end{array}$ & $\begin{array}{c}-6.038 \\
(2.16)\end{array}$ & $\begin{array}{r}-6.254 \\
(2.29)\end{array}$ \\
\hline$P W D_{t}$ & $\begin{array}{c}9.973 \\
(3.93)\end{array}$ & $\begin{array}{r}1.015 \\
(4.13)\end{array}$ & $\begin{array}{l}16.26 \\
(4.44)\end{array}$ & $\begin{array}{l}18.20 \\
(5.11)\end{array}$ & $\begin{array}{l}19.510 \\
(5.36)\end{array}$ & $\begin{array}{l}19.739 \\
(5.35)\end{array}$ & $\begin{array}{l}20.967 \\
(6.01)\end{array}$ \\
\hline Urb.Rur $r_{t-1}^{-1}$ & & & & $\begin{array}{c}-.498 \\
(.85)\end{array}$ & $\begin{array}{l}-.815 \\
(1.42)\end{array}$ & $\begin{array}{l}-.811 \\
(1.37)\end{array}$ & $\begin{array}{r}-1.040 \\
(1.89)\end{array}$ \\
\hline Armfab $_{t-1}$ & & & $\begin{array}{r}-1.965 \\
(2.74)\end{array}$ & $\begin{array}{r}-2.400 \\
(3.36)\end{array}$ & $\begin{array}{c}-2.548 \\
(3.43)\end{array}$ & $\begin{array}{c}-2.417 \\
(3.20)\end{array}$ & $\begin{array}{c}-2.522 \\
(3.37)\end{array}$ \\
\hline$O C_{t-1}$ & & & $\begin{array}{r}-3.285 \\
(1.48)\end{array}$ & $\begin{array}{c}-3.068 \\
(1.34)\end{array}$ & $\begin{array}{r}-2.965 \\
(1.22)\end{array}$ & $\begin{array}{r}-3.217 \\
(1.22)\end{array}$ & $\begin{array}{r}-1.886 \\
(.82)\end{array}$ \\
\hline Fmun $_{t-1}$ & & & $\begin{array}{l}9.114 \\
(.49)\end{array}$ & $\begin{array}{c}14.33 \\
(.75)\end{array}$ & $\begin{array}{c}19.696 \\
(1.00)\end{array}$ & $\begin{array}{l}20.142 \\
(1.01)\end{array}$ & $\begin{array}{l}25.521 \\
(1.32)\end{array}$ \\
\hline$F_{t-1}$ & $\begin{array}{r}.592 \\
(5.74)\end{array}$ & $\begin{array}{r}.480 \\
(4.12)\end{array}$ & $\begin{array}{r}.454 \\
(2.97)\end{array}$ & $\begin{array}{r}.479 \\
(2.84)\end{array}$ & $\begin{array}{r}.579 \\
(3.56)\end{array}$ & $\begin{array}{r}.624 \\
(4.07)\end{array}$ & $\begin{array}{r}.523 \\
(5.39)\end{array}$ \\
\hline $\bar{R}^{2}$ & .98 & .99 & .99 & .99 & .99 & .99 & .99 \\
\hline$h$ & 8.5 & c.n** & c.n. & c.n. & c.n. & c.n & 3.86 \\
\hline$n$ & 27. & 27 & 24 & 25 & 26 & 27 & 27 \\
\hline$a_{j}(\max )$ & 13 & 12 & 10 & 10 & 7.8 & 6 & 3 \\
\hline
\end{tabular}

Notes: ( $t$-statistics in parentheses).

*Tail-end restriction.

*Complex number. in the context of Equation (6). Each version is accompanied by the $\bar{R}^{2}$ and the Durbin $h$-statistics (Durbin 1970), the span of the lagged distribution of marriage rates (i.e. n) and the value of $j$ for which the maximum contribution of marriage rates to current fertility occurs (i.e. $a_{j} \max$ ).

From Table 1 we see that the signs of all explanatory variables comply with the a priori expectations. Equations (1) - (6) of this table have been estimated without imposing any restriction on the structure of the polynomial $a_{j}$. On the other hand, Equation (7) has been estimated by imposing a tail-end restriction; that is, $a_{27}=0$. As can be seen from the results the value of $j$ for which the polynomial $a_{j}$ attains its maximum declines from 13 years down to 3 as we move from Equations (1) to (7) of Table 1. Clearly, the values of $j$ for which $a_{j}$ attains its maximum implied by the first 5 equations are unrealistic. Notice, however, that since these equations do not differentiate between the first and subsequent births, the estimated values for $j$ represent average lengths of intervals between the consummation of marriage and the time at which fertility assumes its maximum value. ${ }^{4}$ Concerning the reported value of $n$, it was chosen in each case as the maximum likelihood estimate. For this, each equation was estimated for values of $n$ ranging from 24 to 27 years. Table 1 presents a typical sample of this effort.

Given the values of the $h$-statistics, Equations (1) and (7) are unequivocally subject to autocorrelation. The reading, however, becomes more difficult in the case of Equations (2) - (6) in which the $h$-statistics becomes a complex number (c.n.) The presence of autocorrelation does not come as a surprise. Indeed, the most frequently met source of autocorrelation is the erroneous specification of the form of the relationship between explained and explanatory variables which, in turn, is a special case of the problem of omitted variables (Johnston 1972, p. 243-244). In particular, although we argued earlier that the relationship between income and fertility is quadratic, Equations (1) - (7) specify it as linear. The resulting estimate of the income coefficient is positive and significant. However, both the sign as well as the presence of autocorrelation are the outcome of the particular specification. Fo approximately 80 percent of the sample observations (roughly those covering the period 1900-1960) the covariance of fertility and income is positive and it turns negative for the remaining 20 percent of the observations. Therefore, the positive relation between income and fertility found for the whole sample period is the inevitable outcome since the negative covariance of the latter period is eclipsed by the positive covariance of the earlier observations. As a result, the linear specification allows the existence of a systematic component in the random term which, in turn, results in autocorrelation.

${ }^{4}$ In this connection it has been estimated (Lee 1977, p. 83) that in 1971 the average interva for births of order 2 and above was 41 months for the age of mothers in the interval 25-29 and 55 months for the age $30-40$. 
We may conclude then that the hypothesis of a non-monotonic Engel's curve, advanced earlier, would be an improvement over the linear hypothesis since it would account for the negative covariance between income and fertility of the latter observations while at the same time it would remove any remaining systematic part of the error term. This specification yields.

$$
\begin{aligned}
& F_{t}=-39.65+.401 \sum_{j} M R_{t-j}+.011 \sum_{j} j M R_{t-j}-.00095 \sum_{j}^{\Sigma j^{2}} M R_{t-j}+ \\
& \text { (2.48) (2.81) (1.28) (1.81) } \\
& 33.48 Y_{p t-1}-6.44 Y_{p t-1}^{2}-6.04 D R_{p t-1}+17.48 P W D_{t-1} \\
& \text { (2.88) (2.69) (2.18) } \\
& .91(\text { Urb/Rur })_{t-1}-2.42 \mathrm{Armfab}_{t-1}-3.22 \mathrm{OC}_{t-1}+ \\
& \text { (1.72) (2.56) (1.03) } \\
& 22.21 \text { Fu }_{t-1}+.35 F_{t-1} \quad \ldots \quad \quad \ldots \quad \ldots \quad \ldots \quad \text { (8) } \\
& \text { (1.13) (3.69) } \\
& \bar{R}^{2}=.99, n=27, a_{j}, \max =5.8, h=2.27
\end{aligned}
$$

Equation 8 reveals the merits of the parabolic specification. The quadratic term in income has resulted in a statistically significant coefficient. Moreover, the use of this variable has succeeded in removing the remaining systematic component of the error term thereby resulting in an equation which is not subject to autocorrelation as the value of the $h$-statistic clearly indicates. It is also interesting to observe that Equation (8) provides us with the threshold level of permanent income; further increases from which result in a decline of fertility. This is found to be $\$ 2,599$. Reference to the sample reveals that this value of permanent income falls in between the years 1958 and 1959 for which the corresponding values of permanent income were $\$ 2,580$ and $\$ 2,653$ respectively. On the other hand, the year for which the birch rate started to decline almost monotonically was 1957 . Therefore, the hypothesis of an income elasticity of fertility which changes signs as income increases is supported by the empirical evidence. ${ }^{5}$ Finally, although Equation (8) is not subjected to a zero tail-end restriction, nevertheless, the last value of $a_{j}$ 's is so close to zero that any further effort in this direction would be superfluous. Indeed, the last coefficient is $a_{27}=.00545$.

So far, we have presented equations in which the various arguments are used in a non-interactive way. We now proceed to test the hypothesis that some of the same arguments act interactively with the variable marriage rates, while others influence fertility directly or in both ways.

${ }^{5}$ Butz and Ward (1980) published estimates of the elasticities of fertility with respect to permanent and current income. They found that the permanent income elasticities are, in general, larger than those which correspond to current income, the former parameter being at least twice as large as the latter. They also found that the female-income elasticity is negative whereas the male-income one is positive, the former being approximately three times as large as the latter regardless whether the elasticities under consideration correspond to permanent or current income. Insofar as they find a positive elasticity of fertility with respect to male income, it might appear that their results contradict ours. This, however, is not so. Our findings are compatible with theirs. To see this, and to cast their results in the same terms as ours, let us disregard all other variables and write.

$$
F=a_{0} M Y+a_{1} F Y
$$

where $F$ denotes fertility, $M Y$ and $F Y$ male and female income respectively. Total differentiation of 5.1 yields.

$$
d F=a_{0} d(M Y)+a_{1} d(F Y)
$$

$\cdots$

$$
\frac{d F}{F}=a_{0} \frac{d(M Y)}{F} \cdot \frac{M Y}{M Y}+a_{1} \frac{d(F Y)}{F} \cdot \frac{F Y}{F Y}
$$

which can be rewritten as

$$
\frac{d F}{F}=e_{F, M Y} \frac{d(M Y)}{M Y}+e_{F, F Y} \frac{d(F Y)}{F Y} \quad \ldots \quad \ldots \ldots
$$

where $e_{F, M Y}$ and $e_{F, F Y}$ denote the elasticity of fertility with respect to male and female incomes respectively. Since Butz and Ward have found that $e_{F, M Y}>0$ and $e_{F, F Y}<0$ and also since 3. $e_{F, M Y} \cong e_{F, F Y}$, we may, therefore, write

$$
\frac{d F}{F} \cong e_{F, M Y}\left[\frac{d(M Y)}{M Y}-3 \frac{d(F Y)}{F Y}\right]
$$

From Equation (5.4) we see that the sign of $d F / F$ depends on the sign of the expression in brackets (since, $e_{F, M Y}>0$ ). The expression in brackets, however, is the differences in the rates of growth of male and female income. During the sample period of Butz and Ward study, which almost coincides with our subperiod during which the income elasticity of fertility turns negative), the rate of growth of these incomes was approximately equal, that is, $d(M Y) / M Y \cong d(F Y) / F Y$ [See e.g. Fucks (1971), and U.S. Department of Census (1978), Table 56]. Therefore, the expression in brackets is negative. This, in turn, agrees with our results which suggest also that $d F / F<0$. 
Since this test entails the introduction of more variables, to conserve observa-

Table 2 tions as well as avoid any multicollinearity, we have truncated Equation (4) to include only income and the divorce rate. Moreover, we introduce the variable oral contraception as an independent one while the variable female unemployment is dropped altogether. Table 2 provides a bird's eye view of the results. ${ }^{6}$

From Table 2 we see that all variables carry the expected signs although multicollinearity has taken its toll. However, the behaviour of residuals, does not exhibit any autocorrelation problem

Moreover, there are some other characteristics of these equations which are of interest. To begin with, comparison of the equations exhibited in Table 2 with Equation (8) as well as those of Table 1 reveals that with the exception of the parabolic coefficients of marriage rates all others are fairly stable. On the other hand, although the value of $j$ 's for which these parabolas attain their maximum values (see, for example Equations (6)-(8) of Table 1 and Equations (9)-(11) of Table 2) does not change considerably, the same cannot be said for the maximum values of the polynomials themselves. However, the final outcome does not change appreciably. This is something which should be expected since the non-decomposed coefficients of marriage rates in Equation (3a) are a weighted algebraic sum as depicted in Equation (4). In particular, the expectation was that all $\alpha j$ 's in Equation (5) would be positive, all $\gamma_{j}$ 's negative, whereas the $\beta_{j}$ 's would be changing signs. For example, the polynomials associated with the interactive term involving income and marriage rate $\left(\beta_{j}\right.$ 's) become negative for $j=17.4, j=24.3$ and $j=20.8$ for the Equations 9,10 and 11 respectively. The means of such a change in the sign of the coefficients, to use for

${ }^{6} \mathrm{~A}$ prototype of this family of parabolas is given in Figure 1. It corresponds to the interactive variable of income and marriages in Equation (9) of Table 2 and it reflects the years 1972 and 1973.

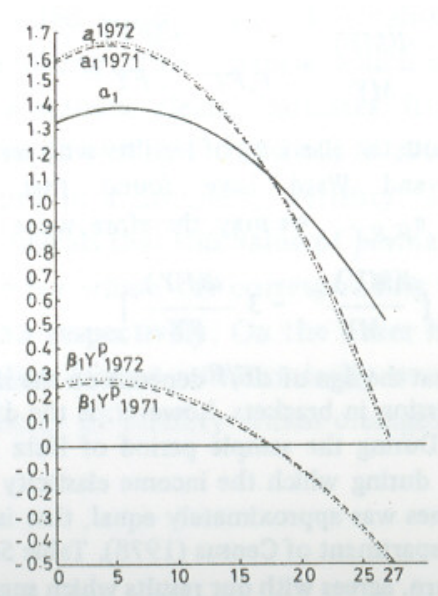

Summary Results from Various Equations

\begin{tabular}{|c|c|c|c|}
\hline \multirow[b]{2}{*}{ Variables } & \multicolumn{3}{|c|}{ Equations } \\
\hline & (9) & (10) & (11) \\
\hline Constant & $\begin{array}{r}-260.29 \\
(2.08)\end{array}$ & $\begin{array}{r}-200.34 \\
(1.97)\end{array}$ & $\begin{array}{r}-360.45 \\
(1.82)\end{array}$ \\
\hline$\sum_{j} M R_{t-j}$ & $\begin{array}{r}1.325 \\
(2.34)\end{array}$ & $\begin{array}{r}.695 \\
(2.44)\end{array}$ & $\begin{array}{r}3.296 \\
(2.21)\end{array}$ \\
\hline$\sum_{j} j M R_{t-1}$ & $\begin{array}{c}.021 \\
(1.65)\end{array}$ & $\begin{array}{c}.0124 \\
(2.28)\end{array}$ & $\begin{array}{l}.0573 \\
(1.59)\end{array}$ \\
\hline $\begin{array}{l}\sum j^{2} M R_{t-1} \\
\sum \\
\Sigma Y_{P, t-1} M R_{t-j} \\
j \\
\Sigma j Y_{P, t-1} M R_{t-j} \\
j \\
\Sigma j^{2} Y_{P, t-1} M R_{t-j} \\
j \\
\Sigma D R_{P, t-1} M R_{t-j} \\
j \\
\Sigma j D R_{P, t-1} M R_{t-j} \\
j \\
\Sigma J^{2} D R_{P, t-1} M R_{t-j}\end{array}$ & $\begin{array}{l}-.00191 \\
(1.61) \\
.0692 \\
(1.89) \\
.00235 \\
(1.86) \\
-.000362 \\
(1.32)\end{array}$ & $\begin{array}{c}-.00102 \\
(1.79) \\
.178 \\
(1.96) \\
.00292 \\
(1.61) \\
-.000451 \\
(1.77)\end{array}$ & $\begin{array}{l}-.0050 \\
(1.82) \\
-.0992 \\
(1.78) \\
.0488 \\
(1.69) \\
-.00211 \\
(1.84) \\
-.264 \\
(1.71) \\
-.0464 \\
(1.59) \\
.00208 \\
(1.23)\end{array}$ \\
\hline$Y_{P, t-1}$ & & $\begin{array}{l}28.41 \\
(3.42)\end{array}$ & $\begin{array}{l}29.35 \\
(2.16)\end{array}$ \\
\hline$Y_{P, t-1}^{2}$ & & $\begin{array}{c}-5.62 \\
(1.91)\end{array}$ & $\begin{array}{c}-5.58 \\
(1.93)\end{array}$ \\
\hline$D R_{t-1}^{P}$ & & $\begin{array}{c}-7.11 \\
(1.98)\end{array}$ & \\
\hline$P W D_{t}$ & $\begin{array}{l}10.67 \\
(4.05)\end{array}$ & $\begin{array}{l}11.47 \\
(5.11)\end{array}$ & $\begin{array}{l}17.59 \\
(4.36)\end{array}$ \\
\hline$U_{t-1}$ & & $\begin{array}{l}-.529 \\
(1.73)\end{array}$ & $\begin{array}{r}-.438 \\
(.89)\end{array}$ \\
\hline Armfab $_{t-1}$ & & $\begin{array}{r}-2.541 \\
(2.54)\end{array}$ & \\
\hline$O C_{t-1}$ & & $\begin{array}{c}-2.09 \\
(1.76)\end{array}$ & $\begin{array}{r}-1.920 \\
(1.01)\end{array}$ \\
\hline$F_{t-1}$ & $\begin{array}{r}.244 \\
(3.42)\end{array}$ & $\begin{array}{r}.254 \\
(2.73)\end{array}$ & $\begin{array}{l}.311 \\
(3.09)\end{array}$ \\
\hline $\bar{R}^{2}$ & $\begin{array}{c}.42) \\
.98\end{array}$ & .99 & .99 \\
\hline$h$ & 2.01 & 2.44 & 1.89 \\
\hline $\begin{array}{l}n \\
\alpha_{j}, \max \end{array}$ & $\begin{array}{l}27 \\
5.5\end{array}$ & $\begin{array}{l}27 \\
6.1\end{array}$ & $\begin{array}{l}27 \\
5.73\end{array}$ \\
\hline$\beta_{j}, \max$ & 3.3 & 3.2 & 11.56 \\
\hline$\gamma_{j}, \max$ & & & 11.15 \\
\hline$\alpha_{j}, \max$ & 4.6 & 4.3 & 5.9 \\
\hline
\end{tabular}

Fig. 1 
instance, the case of Equation (9), is that an increase in income, regardless of its initial level, contributes negatively to the productivity of all those marriages which were consummated seventeen years in the past. Clearly, this is as it should be.

On the other hand, Equation (11) goes one step further to suggest that the parabola, associated with interactive variables income marriage rates, changes signs twice, first at $j=2.6$ and again at $j=20.8$. In other words, income contributes negatively (delays) to conceptions during the first two years and the last six years of the productive span of marriage. To express the same thing differently, an increase in income will accelerate conceptions from the second year of marriage till its twenty-first year although at different rates.

Finally, Equation (11) suggests also that the contribution of divorce rates is uniformly negative as expected. In other words, the perceived risk of divorce induces a postponement in conceptions which in turn affects fertility rates. Furthermore, a comparison of the polynomials associated with the interactive variables (income marriage rates and divorce - marriage rates) shows that the impact of divorce rates is larger than the corresponding influence of income. Figure 2 provides a view of the contribution of the various polynomials in time upon the overall productivity of marriage rates (i.e., $a_{j}$ ) for the year 1973. For this we use Equation (11) of Table 2.

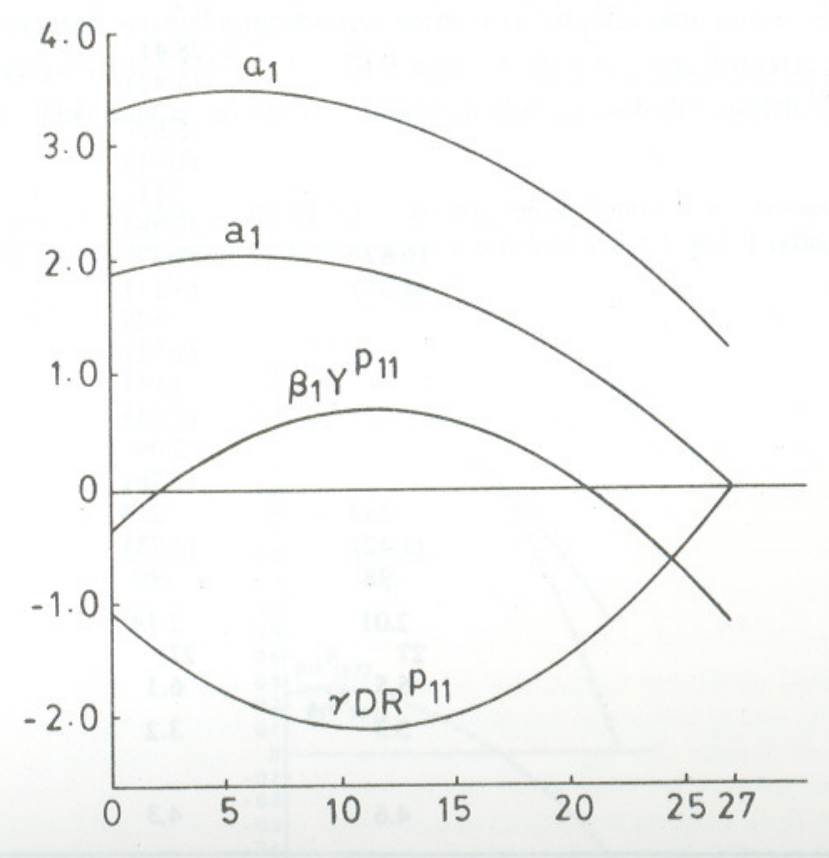

Fig. 2
According to Equation (11) the polynomial $\alpha_{j}$ (i.e. the one associated with marriage rates only (i.e. the constant of Equation 4) achieves a maximum at $j=5.73$, the $\beta_{j}$ (i.e., the one associated with the interactive variable income marriage rates) achieves a maximum at $j=11.56$ and $\gamma_{j}$ (i.e., the one associated with the interactive variable divorce - marriage rates) achieves its maximum at $j=11.15$.

Although we do not have any extraneous information to compare it with these results, intuitively they seem to be reasonable. It is interesting, however, to see that first, the last two interactive polynomials (i.e., the ones associated with income marriage rates and divorce - marriage rates) attain their maximum values almost simultaneously and second, that the impact (the values of the coefficients of the lagged terms) of the divorce - marriage rate polynomial is by far stronger than that of income-marriage rates. The meaning of this relation between these two polynomials is that with the exception of the first two and last six years of the productive life of marriage during which both polynomials are associated with the same signs, during the years in between, the acceleration of births due to income increases is more than offset by the delay due to divorce increases. In fact, this relation persists even when each polynomial is multiplied by its weight (i.e., $Y_{P, t-1}$ and $D R_{P, t-1}$ ) so that their net effect (i.e. their algebraic sum) on the overall productivity of marriages is negative. This can also be seen by reference to Figure 2 .

Equation (11) may also be used to shed more light into the relation of the various explanatory variables. We may ask, for example, if the level of income or divorce rate increases by one percent, by how much the marriage rate has to change so that the level of fertility remains the same. This question is similar to, but should not be confused with, that of elasticity. It is rather associated with the determination of the slopes of an isofertility contour curve. Table 3 provides the relevant estimates for both short and long-run trade-offs expressed for the year $1973 .^{7}$

From Table 3 we can see that in the short-run a one percent increase (decrease) in income can be offset by a two and one half percent increase (decrease) in the marriage rate. Similarly, a one percent increase (decrease) in divorce rate can be compensated by a .57 percent increase (decrease) in the marriage rate. The corresponding figures for the long-run are .013 and 2.04 percent respectively.

On the other hand, a one percent increase (decrease) in income can be offset by a 4.06 and .0064 percent decrease (increase) in the divorce rate in the short and long run respectively. Furthermore, we also see that the percentage changes in marriage rate necessary to compensate a one percent change in income and divorce rate reverse their orders of magnitude in the short and long run. Indeed, while the

${ }^{7}$ The estimation of short-run trade-offs takes into account only the current rates of marriage and divorce rates. On the other hand, the estimation of long-run trade-offs is based on the whole set of lagged marriage and divorce rates by assuming that $M R_{t}=\ldots=M R_{t-n}$ and $D R_{t}=\ldots=$ $D R_{t-n}$ 
Table 3

Estimates for Short and Long Run Trade-offs

\begin{tabular}{llcccc}
\hline & & \multicolumn{3}{c}{$\Delta Y_{P} / Y_{P}$} & \multicolumn{2}{c}{$\Delta D R_{P} / D R_{P}$} \\
\cline { 3 - 6 } & & s.r. & 1.r. & s.r. & 1.r. \\
\hline$\Delta M R / M R$ & s. r. & 2.5 & & .57 & \\
& 1.r. & & .013 & & 2.04 \\
\hline$\Delta D R_{P} / D R_{P}$ & s. r. & -4.06 & & 1.00 & \\
& 1. r. & & -.0064 & & 1.00 \\
\hline
\end{tabular}

required percentage change in marriage rates to compensate a one percent change in income declines as we move from the short to the long run, the opposite is true in the case of changes in divorce rate. This is due to the fact that in the short run the direct effects of one percent change in income are substantial and also that the current interactive term has the same negative sign as the direct effects. Therefore, the marriage rate has to increase accordingly. On the other hand, while in the long run the direct effects are the same as those of the short run, the overall interactive effect of income (i.e., the sum of the coefficients of the lagged terms of the interactive variable income-marriage rates) is positive thereby offsetting the negative direct effects. Furthermore, since in the long-run we take into account the whole stream of marriage rates, the required percentage change becomes smaller. The same can be said for the case of trade-offs between income and divorce rates. However, in the case of trade-offs between divorce rates and marriage rates the importance (i.e., the sum of the coefficients of the lag distribution) of the divorce rate grows faster relative to marriage rate and therefore the required percentage change in marriage rates increases (e.g. $\alpha_{1}=3.296, \sum_{j} \alpha_{j}=79.56, \gamma_{j}=.264, \sum_{j} \gamma_{j}=13.914$ ).

\section{IV}

In this paper we sought to investigate the dynamic response of fertility to changes in some of its determinants. For this we used the framework of a stock adjustment model within which another separate distributed lag between fertility and its explanatory variables unfolds.

The rationale of introducing two separate adjustment mechanisms is to allow us to decompose and estimate separately the effects of marriage rates on fertility on their entire productive span. This decomposition was done in two different levels. First, we assumed that, at each time $t$, fertility depends upon a stream of current and past marriage rates the length of which is determined by the average productive span of a marriage. Second, we argued that the contribution of each marriage rate depends upon the permanent income and divorce rate. In doing so we decompose the contribution of each marriage rate to fertility into (a) a pure marriage effect, (b) an income effect, and (c) a divorce effect. Each of these effects was assumed to follow a parabolic pattern over time which was estimated with the Lagrange interpolation method. Our estimates confirmed our theoretical expectations, namely that the distributed lag of marriage rates has a positive effect on fertility throughout the productive life of marriages; the distributed lag effect of divorce rates is negative; whereas the distributed lag effect of income changes signs. In particular, it was found that the effect of income on fertility is negative during the first two years of marriage, positive during the next eighteen, and turns negative once more for the remaining seven years of the productive life of marriage. The observed'negative effects of income changes on the productivity of marriage rates was hypothesized to be the result of the influence of changing opportunity costs on the timing of births.

Moreover, we argued that income also enters the fertility relation as an independent argument. Our estimates point strongly to the existence of a parabolic direct relation between income and fertility. Therefore, the study provides evidence of a non-monotonic Engel's curve exhibiting a positive (negative) elasticity at relatively low (high) incomes. The demarcation level of income appears to be in the interval of $\$ 2,550<Y_{P, t} \quad<\$ 2,650$. It follows, therefore, that, given tastes, the parabolic relation between income and fertility rates is capable of reconciling previous conflicting estimates of income elasticity of fertility.

However, it would be erroneous to infer from these results that as income grows secularly this inevitably will lead to further reductions in fertility rates. For the direct dampening effect of income on fertility may be cancelled altogether by the indirect income effect on the productivity of marriage rates (see Equation 4 and note that the sum of $a_{j}$ over $j$ increases as income - which is the weight on $\beta_{j}$ increases). Or, to put it another way, a change in income causes a two-fold effect on fertility: a shift of the fertility equation at each time stream of marriages and a change in the relation over time between marriages and fertility. Although the former effect is negative the latter is positive thus, secular income growth, ceteris paribus, need not lead to continued decline in fertility rates. Therefore, on the assumption that the behaviour of divorce and marriage rates does not change and that the annual rate of growth in the permanent per capita income will be in the neighbourhood of 2.5-3.0 percent, we may observe an increase in fertility rates. If so, this will be the outcome of the present age structure of population which may result in such increases in marriage rates which will exceed the corresponding requirements necessary to cancel out the rates of income growth in question.

It is also clear that this proposition will hold a fortori if the rate of growth of permanent income will be less. 


\section{REFERENCES}

Becker, Gary, and Gregg Lewis (1976). "On the Interaction Between the Quantity and Quality of Children". Journal of Political Economy. Part 2. Vol 84, No. 4.

Becker, G. S. (1960). "An Economic Analysis of Fertility". Demugraphic and Economic Change in Developed Countries. Princeton University Press for N.B.E. Butz, William, and Michael Ward (1977). "The Emergence of Countercyclical U.S. Fertility”. Unpublished Manuscript of RAND Corporation, Santa Monica California. Durbin, J. (1970). "Testing for Serial Correlation in Least-Squares Regression when Some of the Regressors are Lagged Dependent Variables". Econometrica, Vol. 38, No. 3. pp. 410-421.

Easterlin, Richard (1973). "Relative Economic Status and the American Fertility Swing". In Eleanor Sheldon (ed.), Social Structure, Family Life Styles and Economic Behavior. Philadelphia: J.B. Lippincott.

Easterlin, Richard (1968). Population Labour Force, and Long Swings in Economic Growth: The American Experience. New York: Columbia University Press.

Easterlin, Richard (1969). "Towards a Socio-Economic Theory of Fertility: A Survey of Recent Research on Economic Factors in American Fertility". Fertility and Family Planning: A World View. Ann Arbor, Michigan: University of Michigan Press.

Easterlin, Richard (1972). “The Relative Income Status and the American Fertility Swing". Institute of Life Insurance.

Festinger, L. A. (1968). "Experiments in Group Belongingness." In H.H. Hyman and E. Singer (ed.). Readings in Reference Group Theory and Research. New York: Free Press.

Friedman, M. (1957). The Consumption Function. Princeton: Princeton University Press.

Fucks, V. (1971). "Differences in Hourly Earnings Between Men and Women". Monthly Labour Review. May. pp. 9-15.

Gregory, Paul, John Campbell and Benjamin Cheng. (1972). "A Simultaneous Model of Birth Rates in the U.S. Review of Economics and Statistics. Vol. 54, No. 4. pp. 374-380.

Hayakawa, H., and Y. P. Venieris (1977). "Consumer Interdependence via Reference Groups". Journal of Political Economy. Vol. 85, No. 3. pp. 599-616.

Inc Magazine: (Various Issues). Boston MA. Inc. Publishing Corp.

Johnston, J. (1972). Econometric Methods (2nd Edition). New York: McGraw-Hill Book Co.

Kelly, H. H. (1968). "Two Functions of Reference Groups". In H. H. Hyman and E. Singer (eds.), Readings in Reference Group Theory and Research. New York: Free Press.
Kuznets, S., and E. Rubin (1954). Immigration and the Foreign Born. New York: N.B.E.R.

Lee, Ronald. (1974). "The Formal Dynamics of Controlled Populations and the Echo, the Boom and the Bust". Demography, Vol. 11, No. 4.

Lee, Ronald (1977). "Fluctuations in U.S. Fertility, Age Structure and Income". Population Studies Center. Ann Arbor, Michigan: The University of Michigan Press.

Miller, D.R. (1963). "The Study of Social Relationships: Situations, Identity and Social Interactions". In S. Kock (ed.), Psychology: A Study of a Science. Vol. 5. New York: McGraw-Hill.

Mincer, J. (1966). "Labour Force Participation and Unemployment: A Review of Recent Evidence". In R.A. Gordon and M.S. Gordon (eds.), Prosperity and Unemployment. New York. pp. 73-112.

Newcomb, T.M. (1968). "Attitude Development as a Function of Preference Group: The Bennington Study". In H. H. Hyman and E. Singer (eds.), Readings in Reference Group Theory and Research. New York: Free Press.

O'Connell, Martin. (1977). "The Effects of Changing Age Distributions on Fertility: an International Comparison". In Julian Simon (ed.), Research in Population Economic. Vol. 1.

Okun, B. (1960). "An Eonomic Analysis of Fertility: Comment". Demographic and Economic Change in Developed Countries. Princeton, New Jersey: Bureau of Economics Research.

Schultz, T.P. (1971). "A Framework for Analysis and its Application to Taiwan's Family Planning Programme". RAND Corporation, Santa Monica, California. p-4674.

Theil, H. (1966). Economic Forecasts and Policy. Amsterdam: North-Holland Publishing Co.

Thomas, D.S. (1960). "The Influence of Business Cycles on Marriages and Birth Rates: Comment". Demography and Economic Change in Developed Countries. Princeton, New Jersey: Bureau of Economic Research.

United States Department of Commerce (Various Issues). Statistical Abstracts of the United States. Washington, D.C.: Bureau of Census.

United States Department of Commerce (1974). Historical Statistics of the United States, Colonial Times to 1970.Washington D.C.: Bureau of Census.

United States Department of Census, (1978). Current Population Report. Washington D.C.

Venieris, Y. P., F.D. Sebold and R. D. Harper (1973). "The Impact of Economic, Technological and Demographic Factors on Aggregate Births". Review of Economics and Statistics, Vol. LV, No. 4. pp. 493-497.

Ward, M. P., and W. P. Butz (1980). "Completed Fertility and Timing". Journal of Political Economy. Vol. 88, No. 51, pp. 917-940.

Watcher, Michael (1975). "A Time-Series Fertility Equation: The Potential for a Baby Boom in the 1980's". International Economic Review. Vol. 16. №. 3. 